\title{
Editorial
}

European

Surgical

Research

Published online: February 13, 2006

DOI: 10.1159/000091477

\section{Persistence after Change: Plans of the New Editor-in-Chief}

It is a pleasure, an honor and a challenge to take over the helm as Editor-in-Chief of European Surgical Research from Professor Messmer, who has guided the journal successfully through the past 16 years. I'll start by introducing myself with some facts about my scientific career: I started working in experimental surgery during medical school at the Institute for Surgical Research in Munich with the late Professor Brendel - co-founder of European Surgical Research. Most of my work was done in neurosurgical research with Professor Baethmann in Munich, Maria Spatz at the NIH and with Giora Feuerstein and John Hallenbeck at the Uniformed Services University in the United States. I returned to Germany to become an assistant professor for surgical research in Munich, and in 1990 moved to Mainz to become Director of the Institute for Neurosurgical Pathophysiology at the Johannes Gutenberg University. Over the past 15 years I have had the chance to work with experts from most surgical disciplines, anaesthesiology as well as cardiology. In joint projects we tried to solve questions concerning the pathophysiology and treatment of brain, heart, liver or small bowel ischaemia, measurement of blood flow and preconditioning. I have been advising researchers about animal protection for 15 years now and I currently head the commission responsible for dissertations and habilitations in our faculty. In addition I review manuscripts for various journals, which has given me quite some experience in refereeing and striving for rigor and impartiality. This experience, I hope, will be valuable when starting this new job.
Ever since the 1970s, it has been the declared aim and scope of European Surgical Research 'to serve the information needs of investigators in various fields of operative medicine', featuring 'original clinical and experimental papers and short technical notes'. I think this should be maintained. As the research field becomes increasingly global, the journal will have to adapt. My goal for the near future, therefore, is to strengthen the position of $\mathrm{Eu}$ ropean Surgical Research in the international field of surgical research, not only attracting European authors but continuing Professor Messmer's intentions to include a growing number of excellent submissions from overseas and Asia.

Another aspect of the journal that will not change is the Editorial Board. The current Board has served the journal for years and is, in fact, the heart of the journal. One name that will be added is that of our new Honorary Editor: Professor Konrad Messmer. The journal and its readers value him for his continuous efforts for European Surgical Research for more than 30 years.

While change can be good, I am not in favour of change for the sake of change. Some changes, however, are necessary. They concern aspects of the journal which require improvement to increase its impact. I intend to promote these changes as quickly as possible. The first aspect is the turnaround of submissions. We are currently generating an electronic manuscript submission platform and will shorten the time from submission to decision to 4 weeks and less. This will not only improve the determination of authors to submit their manuscripts to European Surgical

\begin{tabular}{ll}
\hline KARGER & ( 2006 S. Karger AG, Basel \\
0014-312X/06/0381-0001\$23.50/0 \\
$\begin{array}{l}\text { Fax +41613061234 } \\
\text { E-Mail karger@karger.ch } \\
\text { www.karger.com }\end{array}$ & $\begin{array}{l}\text { Accessible online at: } \\
\text { www.karger.com/esr }\end{array}$
\end{tabular}


Research but also increase the impact factor, as this is calculated as the ratio of articles published in two given years and articles cited by others during this period. A fast turnaround guarantees that articles citing related articles published in European Surgical Research during the two previous years contribute to its impact factor. The longer it takes until a manuscript is published, the more the European Surgical Research articles cited drop out of the two-year window and will not contribute to our impact factor. Authors may also contemplate citing recent European Surgical Research articles in their work submitted to us.

Secondly, short review articles will be included in the journal as soon as possible, limited to one per issue. This will give readers the chance to update their knowledge on new developments more easily. Focus will be on background knowledge from research areas essential to improve surgical research, i.e. molecular biology, pathology, immunology or pathophysiology. Reviews should contain schematic and illustrative drawings, highlight recent findings and address unresolved issues in particular. I encourage authors who have just summarized the current state of the art of their surgical research specialty (e.g. for a grant application) to turn it into a short but conclusive review and to submit it to European Surgical Research.

To conclude, let me invite you, who work in surgical research, to share with us the results of your efforts in the appropriate journal - European Surgical Research! Write for us!

Oliver Kempski, Mainz 